Journal of

International Logistics and Trade

\title{
Transport Connectivity and Regional Development in China
}

\author{
Kevin X. Li, Guanqiu Qi* \\ Department of Trade and Logistics, Chung-Ang University, Seoul, Korea
}

\section{ARTICLE INFO}

Article history:

Received 28 February 2016

Accepted 6 August 2016

Keywords:

Transport connectivity

Panel data

Correlation analysis

Multiple regression analysis

Granger causality analysis

Regional inequalities

\begin{abstract}
This paper examines the relationship between transport connectivity and regional economic development in China. It develops measurements appropriate for transport connectivity based on a set of evaluation models. This model is used to analyze the logistic connectivity of China's 31 provinces by focusing on 11 variables, including some new factors (Density of road network, Density of railway network, Number of Internet Users) not used in previous studies, over the 13-year period from 2002 to 2014. Using panel data regression analysis, the empirical results show a statistically significant and positive impact of transport connectivity (factors like Density of road network, Density of railway network and Number of Internet Users) on economic development in China. In particular, the Number of internet users is a key factor reflecting information connectivity in all the variables. Comparative analysis regarding economic development is conducted to benchmark between coastal provinces and interior provinces. Like most previous research, this study yields the same finding of higher impact of transport connectivity on economic development in eastern provinces than in western provinces. This study suggests that decentralized decision-making will be significantly more efficient for analyzing regional infrastructure development. It also shows that the influence of transport connectivity on economic development is dependent on a certain developmental stage. This suggests that an economic region should adopt different development strategies for transport connectivity during different stages of development.
\end{abstract}

\section{Introduction}

The Chinese expression "Looking for development, building highways first" generalizes the importance of infrastructure on economic growth in the early stage of reform and on the open-door policy. The investment in infrastructure equipment, which has proceeded rapidly and significantly over the past few decades, has contributed significantly to China's economic development and has been a significant driver of economic growth. China's government applied a centralized decision-making structure to all kinds of infrastructure investments, particularly in transportation. More specifically, they favored railway development to satisfy the trade exchange between low-cost-resource provinces and developed ones. With the success of China's reform and global participation since 1978, China has been one of the world's fastest-growing economies, with GDP increasing dramatically from USD 2,168 billion in 1978 to USD 103,588 billion in 2014 according to the National Bureau of Statistics of China.

China's reform and global participation has positively impacted China's economic policies and political model, resulting in changes in society because the political model has driven the success of the economic policy. One of the key features of China's evolution has been the dramatic increase in trade transactions within the country, accompanied by further development of transport connectivity among the provinces. Meanwhile, with the gradual expansion of trade flows involving both domestic and foreign trade, transport connectivity has played an even more important role. Also, it has stimulated the need to develop a logistics market, improve logistics management, and promote hinterland physical

\footnotetext{
* Corresponding author: Department of Trade and Logistics, Chung-Ang University, 84 Heukseok-ro, Dongjak-gu, Seoul, Korea
} Email: zaiguancu@gmail.com 


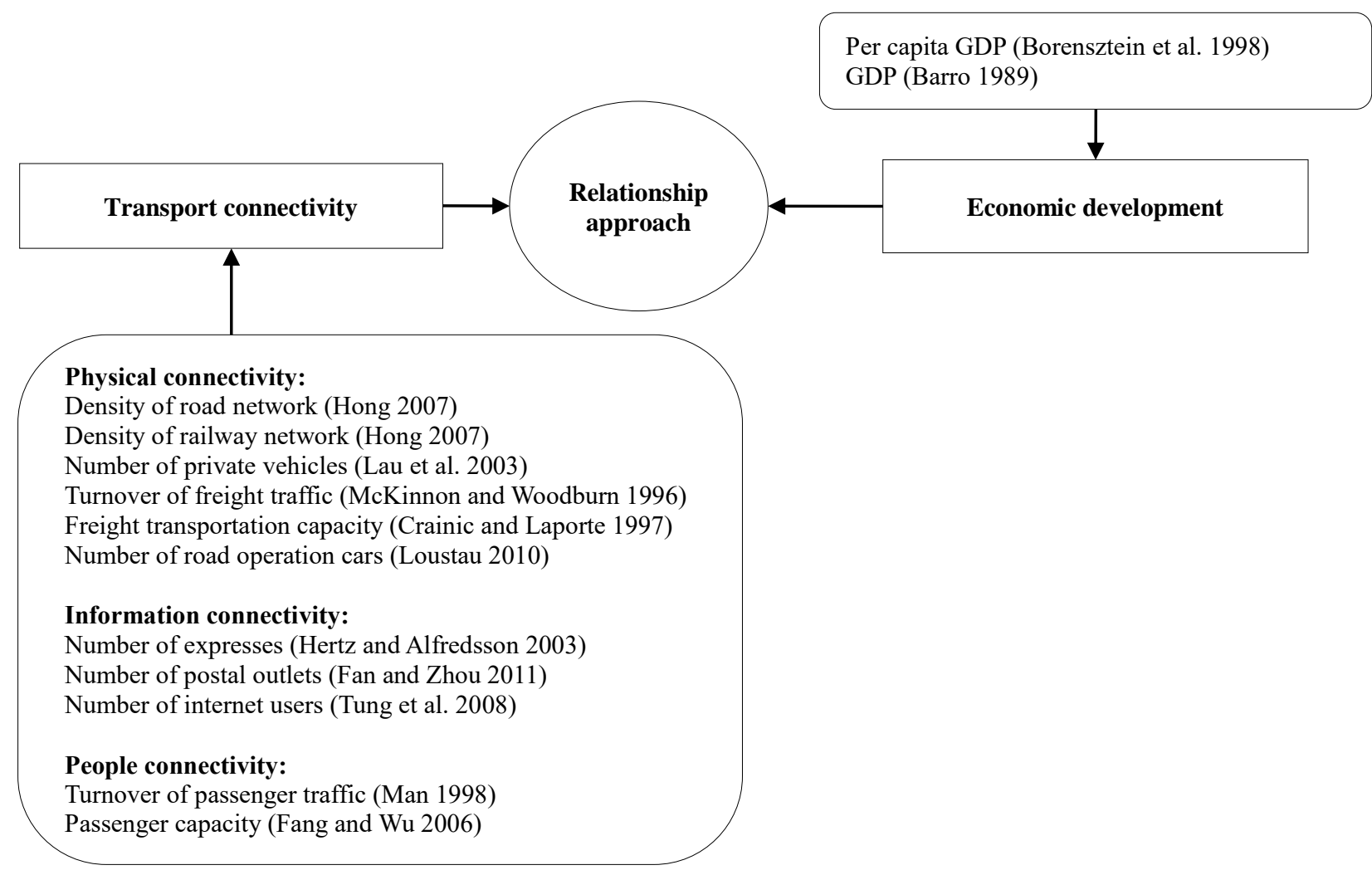

Figure 1. Model of research

infrastructure. China's government has also proposed a new economic paradigm, the One Belt, One Road initiative, which focuses on connectivity and cooperation among mainly Eurasian countries and aims to redirect the country's domestic overcapacity and capital for regional infrastructure development to improve trade and relations with Asian, Central Asian, and European countries (Kennedy and Parker 2015).

Generally speaking, "connectivity" is a form of access between two systems. In the context of transportation planning, connectivity represents the ease, time, or cost of traveling between different transportation route systems or modal systems (Alstadt et al. 2012). This study extends the connectivity definition to all activities to link elements that occur in logistics movements. Transport connectivity links movements of several mechanisms. First, physical connectivity such as transport infrastructure increases the demand for goods and services of customers in different locations. Zhao et al. (2006) identified the railway stations in China as "nodes" and rails as "links" and then generated a railway geographic network to carry cargo or people. As a consequence, some policy-makers have been encouraged to make substantial investments in expanding the nation's transport network, in order to gain benefits from reduced inventories and increased cost savings (Banister and Berechman 2001; Madden and Savage 2000; Mody and Wang 1997; Shirley and Winston 2004; Uchimura 1993). Second, transport connectivity concerns both physical infrastructure and people. Finally, with the rapid installation of computer networks and Information and Communication Technology (ICT), information connectivity plays an important role in promoting economic development and improving the economy (Hernando and Soledad 2004). Information connectivity has become prolific with the widespread use of ICT. These factors have operated as key driving forces to enhance the economic integration of regions in China and to reinforce economic growth. The efficiency gains from logistics information reduce travel time, and passenger and freight transporters gain direct time and cost savings (Bosworth 2000; Closs et al. 2005; Gunasekera et al. 2008). Accordingly, the previous literature suggests that transport connectivity consists of physical, information, and people connectivity. In this paper several factors to the current literature will be added. Key factors of transport connectivity performance are the density of road network, density of railway network, number of private vehicles, turnover of freight traffic, freight transportation capacity, number of highways, number of expresses, number of postal outlets, number of internet users, turnover of passenger traffic, and passenger capacity. Goh (2003) indicated that improvements to China's transportation connectivity to address congestion problems are already underway, though whether an efficient distribution network will develop remains to be seen. Nevertheless, transport connectivity is a great opportunity for China.

Throughout the 1980s, transport connectivity in developed economies was becoming important; for example, in Central and Eastern Europe, researchers focused on the evolution of complicated distribution systems in order to establish efficient supply-chain management (Lorentz 2007; Wang and Cullinane 2006). In the 1990s, however, a stream of research linking transport connectivity to economic development triggered potential research to cover 
developing nations (Speece 1995). Logistics is increasingly recognized as a significant socioeconomic force in developing economies, as found in Russia (Rodnikov 1994); therefore, transport connectivity is now a challenge for developing economies, for example Bangladesh (Razzaque 1997). Because economic development in China has increased remarkably in the last few decades following the socSalist market economy policy (Naughton 2007), transport connectivity for China is not only an opportunity, but also a challenge. Thus, this exploratory research attempts to identify the transport connectivity stage in different regions in China and to motivate policy makers to shape policies to address transport connectivity problems catering for each region.

Given this view, our main goal is to estimate a series of functional models for China's 31 provinces using a panel data dataset for the 13-year period 2002-2014. Two basic models are developed for different cases. The first panel data multiple regression model estimates the relationships among variables. The second, an expanded logarithm multiple regression model previously suggested by Ravallion and Chen (1997), identifies elasticities which then can be used to estimate the variety of various transport connectivity variables for one unit of economic change.

The empirical research presented in this study focuses on connectivity for two reasons. First, roadway and railway networks are often the major components connecting suppliers and consumers within China ${ }^{\text {a }}$. Second, as evidenced by Closs et al. (2005), information connectivity fully mediates the relationship between flexible logistics programs and asset productivity. Therefore, the purpose of this study is to provide more detailed insights into the significance of transport connectivity to economic development in China, using a dataset including 31 provinces over the 13-year period 2002-2014. The specific objectives of this study are shown in Figure 1. The first step is to identify the important factors affecting the transport connectivity in various regions in China; the second is to obtain variables from correlation analysis and estimate if they are statistically significant to economic development; and the third step is to evaluate the contribution of transport connectivity to economic development.

The research is organized as follows. The next section briefly reviews previous studies. Section 3 describes the study area and the source of the dataset, as well as the proposed methodological models that were developed. Section 4 discusses the general analysis results, followed in Section 5 by more detailed across-regions analysis results and discussion. Section 6 and 7 provide the conclusion and policy recommendations.

\section{Literature review}

In general, two types of theories have been proposed in the literature to explain the relationship between transport connectivity and economic growth. First, numerous empirical studies have investigated a significant impact of logistics infrastructure on economic growth. Some former theories have addressed whether transport connectivity contributes to economic growth in terms of further investment in the transport infrastructure, promotion of e-business, and decrease of storage waste (De'murger 2001; Hong et al. 2011). Wang (2010) found that the degree of logistics development is one of the signs of upgrading and establishing national strength and described it as an accelerator in promoting economic development. Shirley and Winston (2004) stated that investment in highways and high-speed railways can bring benefits by reducing inventories and cost-saving, while investment in telecommunications can generate benefits due to improved marketing information (Madden and Savage 2000). Logistics infrastructure leads to economic development through investment in infrastructure itself, reducing travel time and cost and attracting direct foreign investment (Gunasekera et al. 2008; Hong 2007). Ozbay (2007) investigated the impact of highway investments on development and found that private and highway capital had positive, statistically significant impacts on the output, using county-level data from 1990-2000. Ding et al. (2008) found that a telecommunication infrastructure did enhance economic growth, and there was an obvious regional income convergence in China from 1986-2002. Most previous studies have concluded that infrastructure investment in transportation has a strong and positive effect on economic development.

Moreover, some researchers have addressed the idea that transport connectivity and economic development are interrelated, and more attention has therefore been paid to quantitative approaches to examine their relationship. Among them, the Granger causality test is widely used. Bose and Haque (2005) evaluated the direction of causality between the public investment in the transport and communication sectors and economic growth for a set of developing countries and found an association between the two variables due to growth causing investment in the transport and communication sectors, while the reverse relationship was not valid. Nan (2007) pointed out that transport connectivity speed is not significant with rapidly developed economies, but economic growth could attract a huge demand for transport connectivity (Qian 2007). Zheng (2009) used the Granger causality test to analyze the two-way causality between logistics development and economic growth in Guangdong province and found that logistic main-body capability, logistic object capability, and logistic carrier capability all showed one-way causality with the acceleration of economic growth. In addition, Zheng discovered an interaction between regional characteristic capability and economic growth.

\footnotetext{
a "China's high-speed railways hit 3,300 km". News.xinhuanet.com. Retrieved 2012-11-07.

Chinese highways for fast traffic add up to $65,000 \mathrm{~km}(40,389 \mathrm{mi})$ - Chinadaily
} 
To understand the impact of transport connectivity on economic development, other studies, albeit in limited number, have taken into consideration the issue of information connectivity. E-commerce has become a hot issue with the rapid development of computer networks and Information and Communication Technology (ICT), which has played an important role in economic development and profoundly affected the economy (Bosworth 2000). In China, with the development of ICT, e-commerce has entered a stage of large-scale development. The number of Internet users is increasing. The growth and steady improvement of the national economy, business-to-business (B2B) transactions, and the online e-commerce industry have made substantial contributions to the GDP (Lu 2012). Ding et al. (2008) found that the telecommunication infrastructure enhanced economic growth, and there has been an obvious regional income convergence in China.

Finally, recognizing that most of the research had not attempted to take into account comprehensive measurement criteria, previous studies have focused mostly on physical transport connectivity related to road, rail, highway, and so on (Fleisher and Chen 1997). These studies have used cargo turnover and freight volume individually to test the relationship between transport connectivity and economic growth. They have not used some of the available comprehensive data, and their data did not reflect the overall transport connectivity. Rather, those previous studies tended to focus on one type of logistics infrastructure like highway investment or railway length (Fleisher and Chen 1997), which cannot capture the impact of total transport connectivity. Moreover, most studies have concentrated on developed countries or regions. Previous studies have mostly concentrated on finding a relationship between transport connectivity and economic development in the United States and Europe's developed countries. In the case of China, Liu (2012) found that the relationship of Qinhuangdao port logistics and regional economic development with goods growth promoted the increase of the GDP throughput due to Granger causes, but the influence of the reverse was not significant, which indicates that the port logistics development of Qinhuangdao city can improve economic growth. Accordingly, there is an absence of overall analysis in each region. Previous studies have not tested the specific relationship between information connectivity and economic development. This paper attempts to fill these literature gaps.

\section{Data and research methodology}

The sample data were collected from the China National Statistical Yearbook ${ }^{\mathrm{b}}$. Eleven variables were selected and examined among 31 Chinese provinces during 2002-2014. This paper attempted to determine which variable accounts for the largest proportion of economic development. All data were annual data, which were examined by an econometric analytical method, using the per capita GDP as the dependent variable to show the level of economic development.

The variables in this research were selected with the guidance of the previous literature, as shown in Table 1 (Datta and Agarwal 2004; Demurger 2001; Ding et al. 2008). David (2001) applied GDP, physical capital stock, and labor force to the represent development of an economy, while Yang (2011) adopted real GDP per capita in his research to indicate economic growth. Osborne (2002) argued that the addition of many independent variables to the equation resulted in low levels of reliability.

Table 1. Data sources

\begin{tabular}{clll}
\hline Variable & Definition & Reference & Data source \\
\hline$X 1$ & Passenger capacity (million people) & Fang and Wu 2006 & Hong 2007 \\
$X 2$ & Density of road network (ratio) & Loustau 2010 \\
$X 3$ & Number of road operation cars (million) & Man 1998 & Lau et al. 2003 \\
$X 4$ & Turnover of passenger traffic (million passenger-km) & Fan and Zhou 2011 & Yearbook \\
$X 5$ & Number of private vehicles (million) & Hong 2007 & \\
$X 6$ & Number of postal outlets (number) & Hertz and Alfredsson 2003 & \\
$X 7$ & Density of railway network (ratio) & Tung et al. 2008 & \\
$X 8$ & Number of express trains (million pieces) & McKinnon and Woodburn 1996 & \\
$X 9$ & Number of internet users (million people) & Crainic and Laporte 1997 & \\
$X 10$ & Turnover of freight traffic (million tons - km) & Borensztein et al. 1998 & \\
$X 11$ & Freight transportation capacity (million tons) & &
\end{tabular}

First, though most of the 11 parameters were found to affect transport connectivity, in order to ensure the data accuracy of the following regression analysis and eliminate the autocorrelation between variables, we performed correlation analysis. The correlation coefficient is a quantitative measure of the strength of the linear relationship

\footnotetext{
b As was used by Demurger 2001; Datta and Agarwal 2004; Ding et al. 2008
} 
between two variables, where a correlation of 1.0 indicates a perfect linear relationship. Correlation is moderate when the value is greater than 0.6 and high when greater than $0.8^{c}$.

Second, the panel data multiple regression model was adopted, using per capita GDP as a dependent variable and variables derived from correlation analysis as independent variables. "Panel data" refers to a data series of observations of a number of variables, where observations in panel data involve at least two dimensions. In this paper, one was a cross-sectional dimension, indicated by subscript $i$, while the other was a time series dimension, indicated by subscript $t$. The panel data regression model is as follows:

$$
Y_{i t}=\alpha_{i}+\beta X D R O_{i t}+\gamma X N O C_{i t}+\delta X D R A_{i t}+\varepsilon X F T C_{i t}+\zeta X N I_{i t}+\eta X T F T_{i t} \text { for } i=1,2, \ldots, N, t=1,2, \ldots, T
$$

Equation (1) is the panel data multiple regression model. Regression analysis is a statistical process for estimating the relationships among variables (Cook and Weisberg 1982). More specifically, regression analysis helps us to understand how the typical value of the dependent variable changes when any one of the independent variables is varied while the other independent variables are fixed (Dubey 2013).

Third, after estimating the significance of several independent variables, to more accurately determine the impact of individual transport connectivity on economic development, it was deemed necessary to construct a new empirical dataset for converting the original database to a logarithmic form. The type of relationship that we wanted to estimate can be expressed using an expanded logarithm multiple regression version of the model shown in Equation (2), as suggested by Ravallion and Chen (1997), so that elasticities can be interpreted to estimate a variety of various transport connectivity variables for one unit of economic change. Equation (2) has the following form:

$$
\log Y_{i t}=\alpha_{i}+\beta \log D R O_{i t}+\gamma \log N O C_{i t}+\delta \log D R A_{i t}+\varepsilon \log F T C_{i t}+\zeta \log N I_{i t}+\eta \log T F T_{i t}
$$

where $Y_{i t}=$ real GDP per capita in year $t$,

$\log D R O=$ Density of road network in year $t$,

$\log N O C=$ Number of road operation cars in year $t$,

$\log D R A=$ Density of railway network in year $t$,

$\log F T C=$ Freight transportation capacity in year $t$,

$\log N I=$ number of internet users in year $t$,

$\log T F T=$ Turnover of freight traffic in year $t$, and

$\alpha, \beta, \gamma, \delta, \varepsilon, \zeta$ and $\eta$ are coefficients to be estimated.

In addition, $\alpha_{i}$ is a fixed effect reflecting the time differences between provinces, and $\beta, \gamma, \delta, \varepsilon, \zeta$ and $\eta$ represent the "growth elasticity of each variable" with respect to per capita GDP given by $Y_{i t}$.

Fourth, an important question is the existence of a causality relationship between transport connectivity and economic development. The Granger causality test is a statistical hypothesis test for determining whether a one-time series is useful in forecasting another, first proposed by Granger (1969). Granger causality analysis had previously only been used in a pure time series variable until Holtz-Eakin et al. (1988) transferred it into panel data framework. Hood (2008) also illustrated in his study that it would produce more efficient Granger test results with more observations, especially for short time series data. In addition, it must be determined whether transport connectivity causes economic growth or the other way around, if economic growth leads to transport connectivity. To answer this question, we applied the standard Granger causality test.

Finally, factor analysis allowed us to perform a total evaluation of the transport connectivity function based on original variables regarding transport connectivity. Then, with the help of a main-method-panel data model (Cai 2006) with fixed effects, we examined the relationship between transport connectivity and economic growth within function. Physical capital stock and labor force were also considered in the study.

\section{General results and discussion}

First, in reference to Table 2, taking into account the concern about multicollinearity among variables, we reduced the number of variables by checking for high correlation coefficient among variables. We omitted variables for which the correlation coefficient was higher than 0.6 (Bensassi 2015). After eliminating highly correlated variables, we estimated the impact of each variable on the per capita GDP using the model (see Table 3).

Second, to reduce the impact of strong collinearity between independent variables, we chose a "cross-section-weights" model, a feature available in E-views 8.0 software package, to adjust the heteroscedasticity in

\footnotetext{
c According to Bensassi's study, they removed a variable to avoid multicollinearity problems with high correlation in the estimated equations
} 
panel data among the chosen variables. A regression model was firstly estimated as a benchmark model. The results from Table 4 show that DRA, DRO and NI had significant effects on per capita GDP. Next, before estimating the panel data model, the Hausman test was used for model selection, where the null hypothesis is that the preferred model is random effects rather than fixed effects (see Table 5). With the $p$-value smaller than 0.05 , the fixed effects model was suggested. Table 6 illustrates that DRA, DRO and NI were significant at a 0.1 level contribution to economic growth, while NOC, FTC and TFT were not significant to economic growth.

Table 2. Pearson correlation results between 11 variables and transport connectivity

\begin{tabular}{|c|c|c|c|c|c|c|c|c|c|c|c|}
\hline $\mathrm{P}-\mathrm{C}$ & $\mathrm{PC}$ & DRO & NOC & TPT & $\mathrm{NCV}$ & $\mathrm{NP}$ & DRA & $\mathrm{NE}$ & NI & TFT & FTC \\
\hline $\mathrm{PC}$ & 1 & & & & & & & & & & \\
\hline DRO & $0.539 * *$ & 1 & & & & & & & & & \\
\hline NOC & $0.646 * *$ & $0.595 * *$ & 1 & & & & & & & & \\
\hline TPT & $0.862 * *$ & $0.686^{* *}$ & $0.771 * *$ & 1 & & & & & & & \\
\hline $\mathrm{NCV}$ & $0.691 * *$ & $0.523 * *$ & $0.750 * *$ & $0.730 * *$ & 1 & & & & & & \\
\hline $\mathrm{NP}$ & $0.709 * *$ & $0.546^{* *}$ & $0.621 * *$ & $0.709 * *$ & $0.708 * *$ & 1 & & & & & \\
\hline DRA & $0.112 *$ & $0.535 * *$ & $0.391 * *$ & $0.317 * *$ & $0.256^{* *}$ & $0.212 * *$ & 1 & & & & \\
\hline $\mathrm{NE}$ & $0.438 * *$ & $0.136^{*}$ & $0.333 * *$ & $0.395^{* *}$ & $0.699 * *$ & $0.649 * *$ & -0.051 & 1 & & & \\
\hline NI & $0.772 * *$ & $0.558 * *$ & $0.509 * *$ & $0.788 * *$ & $0.933 * *$ & $0.736^{* *}$ & $0.209 * *$ & $0.717 * *$ & 1 & & \\
\hline TFT & $0.248 * *$ & 0.087 & $0.414 * *$ & $0.368 * *$ & $0.505 * *$ & $0.347 * *$ & 0.050 & $0.418 * *$ & $0.509 * *$ & 1 & \\
\hline FTC & $0.558 * *$ & $0.524 * *$ & $0.473 * *$ & $0.609 * *$ & $0.777 * *$ & $0.639 * *$ & $0.420 * *$ & $0.423 * *$ & $0.576^{* *}$ & $0.597 * *$ & 1 \\
\hline
\end{tabular}

** Correlation is significant at the 0.01 level (2-tailed).

* Correlation is significant at the 0.05 level (2-tailed).

Table 3. List of independent variables and the dependent variable after Pearson correlation analysis

\begin{tabular}{ccc}
\hline Variable & Definition & Acronym \\
\hline$X 1$ & Density of road network (ratio) & DRO \\
$X 2$ & Number of road operation cars (million) & NOC \\
$X 3$ & Density of railway network (ratio) & DRA \\
$X 4$ & Number of internet users (million people) & NI \\
$X 5$ & Turnover of freight traffic (million ton - km) & TFT \\
$X 6$ & Freight transportation capacity (million tons) & FTC \\
$Y$ & Per capita GDP (Yuan) & PGDP \\
\hline
\end{tabular}

Table 4. Cross-section random effects according to pooled regression results

\begin{tabular}{ccccc}
\hline Variable & Coefficient & Std. error & t-statistic & Prob. \\
\hline C & -4308.487 & 1949.140 & -2.210455 & 0.0276 \\
DRA & 956838.2 & 70970.83 & 13.48213 & 0.0000 \\
DRO & 6116.981 & 2095.150 & 2.919591 & 0.0037 \\
FTC & 0.888367 & 1.529937 & 0.580656 & 0.5618 \\
TFT & -0.001308 & 0.002667 & -0.490305 & 0.6242 \\
NI & 917.7201 & 73.43807 & 12.49652 & 0.0000 \\
NOC & -1983.430 & 2852.609 & -0.695304 & 0.4873 \\
R-square & 0.742774 & & & \\
F-statistic & 190.5840 & & & \\
Prob(F-statistic) & 0.000000 & & & \\
\hline
\end{tabular}

Table 5. Correlated random effects according to the Hausman Test

\begin{tabular}{ccccc}
\hline & \multicolumn{3}{c}{ Test cross-section random effects } & \\
\hline Test summary & Chi-Sq. statistic & Chi-Sq. d.f. & Prob. \\
Cross-section random & 87.271080 & 6 & 0.0000 \\
\hline
\end{tabular}


Finally, from the results shown in Table 7, the adjusted $\mathrm{R}^{2}$ and the overall $\mathrm{F}$ statistics indicate that the model fitted the data very well. The results of logarithm multiple regression analysis demonstrated that the number of Internet users had a significant effect on per capita GDP, as reflected by a positive and significant value $(p=0.0000)$. Elasticity analysis indicated that one unit of change in transport connectivity induced one unit of change in economic growth. The coefficient between the number of internet users and per capita GDP was 0.404514, which means that a one unit increase in the number of Internet users increased the per capita GDP by 0.404514 units. Clearly, most inputs had a significant and positive effect on economic growth.

Using the analysis of the logarithm regression model, the number of internet users reflected the most relative with PGDP than with other variables. Table 8 reports the F-statistics and probability values constructed under the null hypothesis of no causality in the number of internet users. Rejection of the null hypothesis was not a Granger-cause of effect on per capita GDP in 23 provinces, which implies that the number of internet users had a Granger-effect on the dependent variable. On the contrary to the null hypothesis, which assumes a dependent variable has a Granger cause, internet user number had a significant effect in just 10 of the provinces. Table 9 reveals that the relationship between transport connectivity and economic development was bidirectional except for the number of roads.

Subsequent to the empirical analysis, the number of internet users showed an important effect on per capita GDP. The number of internet users as measured by the logarithm regression analysis had a unique effect on per capita GDP. The significant impact of internet user numbers on the economy in China justifies the necessity of policy change. The number of internet users is the most powerful factor for stimulating economic development in certain provinces.

Table 6. Cross-section weights according to the fixed-effects model

\begin{tabular}{|c|c|c|c|c|}
\hline Variable & Coefficient & Std. error & t-statistic & Prob. \\
\hline $\mathrm{C}$ & -11743.02 & 1620.914 & -7.244690 & 0.0000 \\
\hline DRA & 1361051. & 95192.25 & 14.29792 & 0.0000 \\
\hline DRO & 5910.703 & 1180.878 & 5.005344 & 0.0000 \\
\hline FTC & 0.394526 & 1.023574 & 0.385440 & 0.7001 \\
\hline TFT & 0.000615 & 0.002556 & 0.240682 & 0.8099 \\
\hline NI & 870.6881 & 49.83018 & 17.47311 & 0.0000 \\
\hline NOC & -2155.263 & 1905.743 & -1.130930 & 0.2588 \\
\hline $\mathrm{R}$-square & 0.947438 & & & \\
\hline F-statistic & 183.2554 & & & \\
\hline Prob(F-statistic) & 0.000000 & & & \\
\hline
\end{tabular}

Table 7. Logarithm regression results

\begin{tabular}{ccccc}
\hline Variable & Coefficient & Std. error & t-statistic & Prob. \\
\hline C & 3.970680 & 0.079540 & 49.92063 & 0.0000 \\
LDRA & 0.151615 & 0.019898 & 7.619438 & 0.0000 \\
LDRO & 0.196189 & 0.030217 & 6.492718 & 0.0000 \\
LFTC & 0.176934 & 0.025693 & 6.886432 & 0.0000 \\
LTFT & 0.246721 & 0.027823 & 8.867642 & 0.0000 \\
LNI & 0.404514 & 0.015988 & 25.30113 & 0.0000 \\
LNOC & 0.125590 & 0.025908 & 4.847564 & 0.0000 \\
R-square & 0.978699 & & & \\
F-statistic & 481.7822 & & & \\
Prob(F-statistic) & 0.000000 & & & \\
\hline
\end{tabular}

\section{Discussion}

The Chinese "open-door policy" is usually highlighted as the main engine of economic growth. However, some new problems have arisen during China's transition to a market-based economy. One of the important characteristics of the Chinese economy is a growing inequality in per capita income between coastal and interior provinces. Policy makers can use the results of this study to determine the investment of logistics infrastructure for economic development and to achieve balanced growth, as well as to reduce disparities among regions. These appear to be major policy challenges in present day China. To address this, we first estimated the relationship between transport connectivity and economic development in a consolidated manner and then performed an analysis across different regions in China. 
Table 8. Granger causality test results of the number of internet users

\begin{tabular}{|c|c|c|c|}
\hline Null hypothesis & F-statistic & Null hypothesis & F-statistic \\
\hline \multicolumn{2}{|c|}{ NI does not Granger-cause PGDP } & \multicolumn{2}{|c|}{ PGDP does not Granger-cause NI } \\
\hline Neimenggu & $0.0219 * *$ & Shanghai & $0.0493 * *$ \\
\hline Heilongjiang & $0.0655^{*}$ & Jiangsu & $0.0026 * * *$ \\
\hline Jiangsu & $0.0005 * * *$ & Zhejiang & $0.0728 *$ \\
\hline Zhejiang & $0.0018 * * *$ & Anhui & $0.0068 * * *$ \\
\hline Anhui & $0.0003 * * *$ & Henan & $0.0283 * *$ \\
\hline Fujian & $0.0017 * * *$ & Hubei & $0.0566^{* *}$ \\
\hline Jiangxi & $0.0009^{* * *}$ & Guangdong & $0.0664 *$ \\
\hline Shandong & $0.0006^{* * *}$ & Guangxi & $0.0202 * *$ \\
\hline Henan & $0.0006^{* * *}$ & Hainan & $0.0024 * * *$ \\
\hline Hubei & $0.0011 * * *$ & Chongqing & $0.0895^{*}$ \\
\hline Guandong & $0.0024 * * *$ & & \\
\hline Guangxi & $0.0004 * * *$ & & \\
\hline Hainan & $0.0008 * * *$ & & \\
\hline Chongqing & $0.0039 * * *$ & & \\
\hline Sichuan & $0.0004 * * *$ & & \\
\hline Guizhou & $0.0007 * * *$ & & \\
\hline Yunnan & $0.0005 * * *$ & & \\
\hline Xizang & $0.0026^{* * *}$ & & \\
\hline Shanxi & $0.0001 * * *$ & & \\
\hline Gansu & $0.0015 * * *$ & & \\
\hline Qinghai & $0.0032 * * *$ & & \\
\hline Ningxia & $0.0015 * * *$ & & \\
\hline Xinjiang & $0.0134 * *$ & & \\
\hline
\end{tabular}

NOTE: Tests for causality were carried out for one variable (number of internet users) in 31 provinces using the model in E-VIEWS 6.0. ***,**, and $*$ indicate significance at the $1 \%, 5 \%$, and $10 \%$ levels, respectively.

Table 9. Granger causality test results cross sections

\begin{tabular}{cccc}
\hline Null hypothesis: & Obs. & F-statistic & Prob. \\
\hline TFT does not Granger-cause PGDP & 341 & 6.66483 & 0.0015 \\
PGDP does not Granger-cause TFT & 341 & 4.30652 & 0.0142 \\
PGDP does not Granger-cause NOC & 341 & 0.62274 & 0.5371 \\
NOC does not Granger-cause PGDP & 341 & 0.16802 & 0.8454 \\
PGDP does not Granger-cause NI & 341 & 2.56520 & 0.0784 \\
NI does not Granger-cause PGDP & 341 & 1.36223 & 0.2575 \\
PGDP does not Granger-cause DRO & 341 & 2.00574 & 0.1362 \\
DRO does not Granger-cause PGDP & 341 & 4.06071 & 0.0181 \\
PGDP does not Granger-cause FTC & 341 & 3.81185 & 0.0231 \\
FTC does not Granger-cause PGDP & 341 & 2.44592 & 0.0882 \\
PGDP does not Granger-cause DRA & 341 & 9.39313 & 0.0001 \\
DRA does not Granger-cause PGDP & 341 & 3.12036 & 0.0454 \\
\hline
\end{tabular}

We used factor analysis to achieve dimension reduction and simplicity. First, the suitability of factor analysis was demonstrated by the Kayser-Mayer-Olkin (KMO) statistic (KMO $>0.7$ and Bartlett's test $\mathrm{P}<0.05)$. After this, the original indicators were divided into four groups with the help of the principal component analysis method, reflecting the original factor structure evaluation information. Then, according to the score and coefficient of each factor, using the variance contribution rate of each of the main factors as the weight proportion of the total variance contribution rate of a re-weighted average, a comprehensive evaluation model was developed:

$$
F=0.6014 F 1+0.1856 F 2+0.1104 F 3+0.1025 F 4
$$


where $F$ indicates the transport connectivity composite situation score, and $F 1-F 4$ factors represent the factor scores calculated by the factor score function. A higher score of $\mathrm{F}$ means a higher level of transport connectivity.

Second, to estimate the panel model with fixed effects, the following steps were taken. In step 1, we determined whether the series is stationary or not. From this analysis, we found that all variables were stationary after taking a first difference. Following Levin, Lin, and Chu (2002), Augmented Dickey-Fuller (ADF) was applied, and more specifically the ADF-Fisher unit root tests provided in E-views 8.0. In step 2, as indicated by the Kao residual co-integration test and Pedroni residual co-integration test, the $\mathrm{p}$ value was 0 , which signified the significant impact of transport connectivity on economic growth. In addition, a long-term equilibrium relationship was suggested between transport connectivity and economic growth. In step 3, we estimated a regression model as a benchmark model. From Table 10, a logarithm regression model was developed in which " $k$ " is the log value of capital and "l" the log value of label. The coefficient of the relationship between F (transport connectivity composite situation score) and GDP was 0.232, which means that a one-unit increase in logistics development increased the total GDP by 0.232 units with, ceteris paribus, no change of other independent variables. It is clear that all inputs involving capital, labor, and transport connectivity made a significant and positive contribution to economic growth, which is reflected by the corresponding p-values. Moreover, the economy demonstrated a slight effect of increasing return to scale because the sum of all coefficients except a constant was greater than one.

Table 10. Linear regression results

\begin{tabular}{cccc}
\hline Variable & Coefficient & t-statistic & Prob. \\
\hline C & 0.563 & 13.09 & 0.000 \\
K & 0.452 & 18.83 & 0.000 \\
L & 0.364 & 15.83 & 0.000 \\
F & 0.232 & 19.30 & 0.001 \\
R-square & 0.9536 & & \\
Prob(F-statistic) & 0.000000 & & \\
\hline
\end{tabular}

The next step was to estimate the panel data model. According to the p-value in the Hausman test (smaller than 0.05), a fixed effect model was suggested rather than a random-effects model. Table 11 shows the estimation results, illustrating that the coefficient of transport connectivity is 0.494 , which is positive and significant, indicating a significant, positive impact of transport connectivity on economic growth. Moreover, from the perspective of elasticity, a one-unit change in transport connectivity induced a 0.494 unit change in economic growth. Comparing the contribution of labor and transport connectivity to economic growth, it is clear that transport connectivity was more important.

Table 11. Fixed-effects model

\begin{tabular}{cccc}
\hline Variable & Coefficient & t-statistic & Prob. \\
\hline C & 0.582 & 12.90 & 0.000 \\
LNK & 0.553 & 19.75 & 0.000 \\
LNL & 0.467 & 16.10 & 0.000 \\
LNF & 0.494 & 35.30 & 0.001 \\
R-square & 0.9637 & & \\
Prob> chi2 $=$ & 0.000000 & & \\
\hline
\end{tabular}

Finally, to investigate the disparities of the impact of transport connectivity on economic growth, cross-region analysis was also conducted. To identify the impact of transport connectivity on economic growth across regions, we classified the provinces into four regions (see Figure 2) based on geographical location. One of the fundamental characteristics of the Chinese economy is unequal development across regions: the developed eastern coastal region, the developing central region, and the left-behind western region. The classification is preferred because there is a significant difference in growth rates and transport connectivity between the coastal provinces and interior provinces and, on average, the coastal region is better developed than the interior region and others regions:

1. Eastern region: Beijing, Tianjin, Hebei, Shanghai, Jiangsu, Zhejiang, Fujian, Shandong, Guangdong, and Hainan. (See Figure 2: region 1)

2. Northeast region: Liaoning, Jilin, and Heilongjiang. (See Figure 2: region 2)

3. Central region: Shan-xi, Anhui, Jiangxi, Henan, Hubei, and Hunan. (See Figure 2: region 3) 
4. West region: Inner Mongolia, Guangxi, Chongqing, Sichuan, Guizhou, Yunnan, Tibet, Shaanxi, Gansu, Qinghai, Ningxia, and Xinjiang. (See Figure 2: region 4)

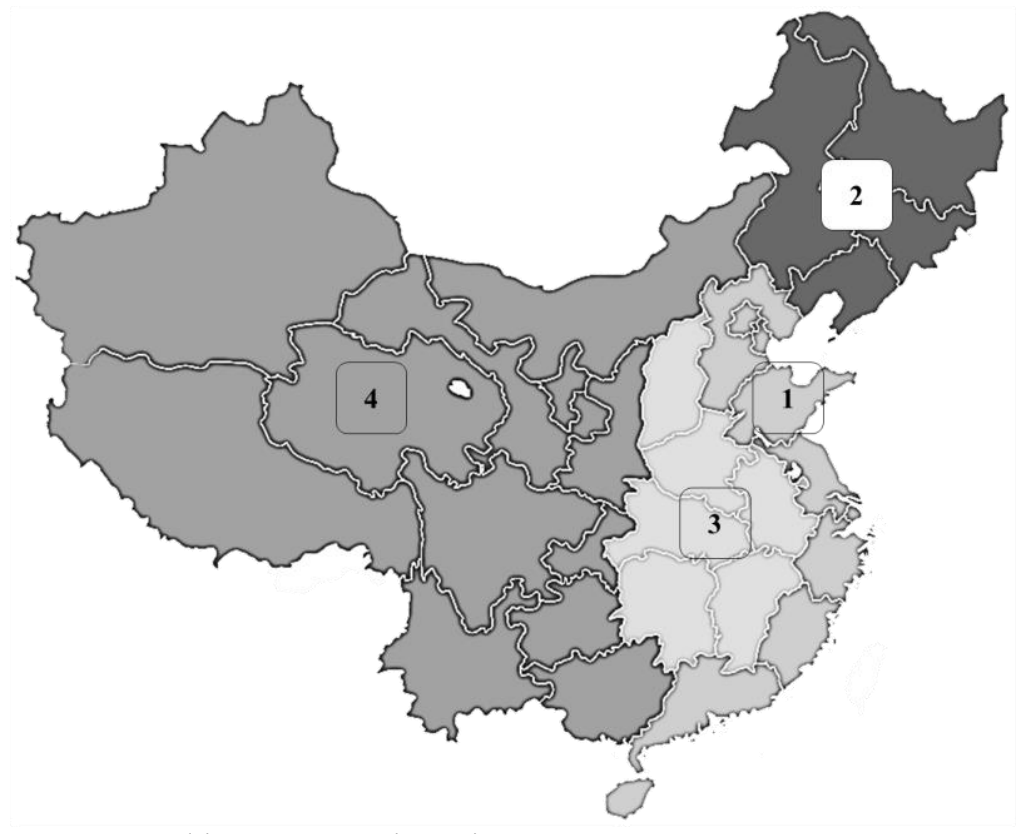

Figure 2. Chinese economic regions

We performed a comparative analysis, and the estimation results regarding the transport connectivity are shown in Table 12. "LNF" is the comprehensive transport connectivity level in this area. With regard to the relationship of LNF with GDP, a similar panel data analysis was carried out among various regions. As shown in Table 12, the $p$ value was less than 0.05. More specifically, the coefficient of the LNF of the eastern region and GDP was 0.526, indicating the highest contribution of transport connectivity to economic growth in this region, followed by the northeast region, central region, and the western region. These results indicated that the Chinese government should focus on a connectivity policy for the interior of China in order to reduce regional inequality.

Table 12. Comparison of regions using a fixed effects model

\begin{tabular}{ccc}
\hline Variable & Coefficient & Prob. \\
\hline F ER & 0.526 & 0.000 \\
F NR & 0.195 & 0.028 \\
F CR & 0.136 & 0.002 \\
F WR & 0.124 & 0.005 \\
\hline
\end{tabular}

Despite the rapidly increasing development of modern logistics in China in recent years, China's transport connectivity remains the primary modern logistics concern. Some provinces like Hubei and Henan, which are located inland with lower intensification, specialization, and standardization, had low levels of accessibility compared with those in coastal developed areas like Shanghai, Zhejiang province. Fortunately, in recent years, the government has taken some measures to address the problem of regional inequality, by developing transport connectivity systems in western and central China. According to the sequences of such connectivity introduction in each province, the level of economic development varies in each province. With today's economic globalization and ICT, each province in China must take advantage of the favorable logistics development to seize the opportunity to achieve a sustainable economic growth strategy.

\section{Conclusion}

This paper investigated the impact of transport connectivity on economic development while taking into consideration important theoretical issues such as "cross-section regression," "causality relationship," and "elasticity" using econometric models and a database of information from 31 provinces in China from the 13-year period of 20022014. The results of our analysis of the panel data regression model and Granger causality provided further evidence 
enriching the result of previous research on the impact of transport connectivity on economic growth. We also found that transport connectivity was more important to economic growth than the contribution of labor. Moreover, we found that transport connectivity made the highest contribution to economic growth in the eastern region, followed by the northeast region, the central region, and finally by the western region. It is quite apparent that the Chinese central government should pay particular attention to the western part of China and work to reduce regional inequality between the eastern and western parts of China.

Another important issue that requires attention is that the number of internet users is crucial for information connectivity, indicating that the role of information connectivity towards economic growth is currently more significant than the traditional infrastructure reported in the literature. Goh and Ling (2003) reported that the internet is the main means of rapid industrialization and economic development and indicated that the role of internet users is to connect China to the rest of the world. Another important issue is the regional inequalities in transport connectivity between coastal and interior provinces are reflected not only from a consolidated perspective, but also in a cross-section analysis. Considering China's size, geographic differences in infrastructure investment are not surprising and may extensively influence the economic development in each province. Table 12 shows that the correlation coefficient of GDP in the eastern region is 0.526 , the highest in the country. Based on this result, China should balance these disparities between western and eastern regions in order to achieve economic and political equality.

To summarize, the following major conclusions are drawn:

- As suggested from the fixed effects model, the density of road network, density of railway network and the number of internet users had positive, statistically significant impacts on PGDP.

- The number of internet users was a key factor reflecting information connectivity.

- The internet users Granger-causes the dependent variable PGDP was observed.

- The coefficient of logistic connectivity and GDP in the eastern region was 0.526 , and was the highest contribution to economic growth in the country, followed by the northeast region, central region, and the lowest contribution in the western region.

- The results of our research model revealed that the level of economic development depends not only on the economic model of current China, but also on government political and economic policies that play an important role in the transport connectivity infrastructure.

Some political implications can be derived from this research.

First, this paper expands the definition of "transport connectivity" to encompass information infrastructure, people-connecting activity, and related services. Most of the previous studies highlighted the significant effect of physical connectivity on economic development. This study has also shown that information connectivity is an important determinant in promoting economic development and hence should be taken into account in government policies to attract investment. These results therefore support the general idea that investment in information connectivity is a key point in China's economic growth.

Second, this study investigated the relationship between transport connectivity and economic development; transport connectivity performance was found to have a different impact among different regions in China. As shown in Table 12, for example, transport connectivity in Shanghai and Tianjin located in the eastern region had a higher elasticity growth impact on economic growth than did that in western regions like Inner Mongolia. This highlights that transport connectivity in the eastern and northeast regions are well established, but more organizational investment and economic stimulus are needed in the central and western regions. Therefore, regions are classified as developed, less-developed, and least-developed based on developmental stage.

- Developed regions: Beijing, Tianjin, Hebei, Shanghai, Jiangsu, Zhejiang, Fujian, Shandong, Guangdong, Hainan, Liaoning, Jilin, Heilongjiang;

- Less-developed regions: Shan-xi, Anhui, Jiangxi, Henan, Hubei, Hunan; and

- Least-developed regions: Inner Mongolia, Guangxi, Chongqing, Sichuan, Guizhou, Yunnan, Tibet, Shaanxi, Gansu, Qinghai, Ningxia, Xinjiang.

Third, one of the important lessons of the empirical analysis is that central planning of logistical development causes some distortion problems, i.e., an unbalanced development stage is presented in different regions. Nonetheless, in a developed region, some aged infrastructure may become inadequate to meet the newer and vibrant demand, which naturally leads to a high up-front logistics cost, while simultaneously the need for updating of outdated facilities is also becoming a problem. Because the less-developed regions include large provinces in the central region between the eastern and western regions of China, the regional government should pay particular attention to development planning by identifying this region as a hub-region.

Finally, policy makers should be aware of the strong disparities among developed regions, less developed regions, and least developed regions. China faces the challenge of enhancing the growth potential of less or least developed regions through appropriate economic policies. Actually, Chinese authorities have focused on regional development 
policies since the 1990s in order to dampen the rising inequality and have decided to use state investment to stimulate domestic economic development. With China's Western Development Program, although the Chinese government focused on helping to develop the coastal (eastern) region first, in late 1999, Chinese leaders announced a western development program to promote the development of the interior region's transport infrastructure by building a road networks, railway system, and airports. Most of the investments were used to develop transportation, energy, and communication in the western regions (Lai 2002). Subsequently, the Chinese government established a "north-east revival strategy" and "the rise of central China" programs to achieve development of the economy in western and northeast regions (Chen and Zheng 2008). OBOR could be another powerful economic policy to stimulate development of domestic regional economics. The western regions would definitely benefit from these development programs. Accordingly, this paper suggests that the government should continue to intensify investment in supporting infrastructure along with human resources, policies, and regulations.

\section{Acknowledgement}

This research was supported by the Chung-Ang University Research Scholarship Grants in 2014.

\section{References}

Adams, R.H., 2004. Economic growth, inequality and poverty: estimating the growth elasticity of poverty. World Development 32 , 1989-2014.

Agénor, P.R., 2010. A theory of infrastructure-led development. Journal of Economic Dynamics and Control 34, 932-950.

Akaike, H., 1978. Factor analysis and AIC. Psychometrika 52, 317-332.

Alstadt, B., Weisbrod, G., Cutler, D., 2012. Relationship of transportation access and connectivity to local economic outcomes. Transportation Research Record: Journal of the Transportation Research Board 2297, 154-162.

Balaguer, J., Cantavella-Jorda, M., 2002. Tourism as a long-run economic growth factor: the Spanish case. Applied Economics 34, 877-884.

Banister, D., Berechman, Y., 2001. Transport investment and the promotion of economic growth. Journal of Transport Geography 9 , 209-218.

Banister, D., Thurstain-Goodwin, M., 2011. Quantification of the non-transport benefits resulting from rail investment. Journal of Transport Geography 19, 212-223.

Barro, R.J., 1989. Economic growth in a cross section of countries. National Bureau of Economic Research.

Bensassi, S, Márquez-Ramos, L., Martínez-Zarzoso, I., Suarez-Burguet, C., 2015. Relationship between logistics infrastructure and trade: evidence from Spanish regional exports. Transportation Research Part A: Policy and Practice 72, 47-61.

Blumberg, D.F., 1998. Strategic examination of reverse logistics and repair service requirements, needs, market size, and opportunities. Annual Conference Proceedings, Council of Logistics Management.

Borensztein, E., De Gregorio, J., Lee, J.W., 1998. How does foreign direct investment affect economic growth?. Journal of International Economics 45, 115-135.

Bose, N., Haque, M.E., 2005. Causality between public investment in transport and communication and economic growth. Journal of Economic Development 30, 95-106.

Bosworth, B.P., Triplett, J.E., 2000. What's new about the new economy? IT, economic growth and productivity. Brookings Institution, Mimeo.

Cai, D.P., 2006. Statistical analysis of the modern logistics industry and the national economy. Logistics 21, 74-75.

Chen, M., Zheng, Y., 2008. China's regional disparity and its policy responses. China \& World Economy 16, 16-32.

Closs, D.J., Morgan, S., Anand, N., 2005. The role of information connectivity in making flexible logistics programs successful. International Journal of Physical Distribution \& Logistics Management 35, 258-277.

Cook, R.D., Weisberg, S. 1982. Criticism and influence analysis in regression. Sociological Methodology 13, 313-361.

Cooper, J.C.B., 2003. Price elasticity of demand for crude oil: estimates for 23 countries, OPEC Review 27, 1-8.

Crainic, T.G., Laporte, G., 1997. Planning models for freight transportation. European Journal of Operational Research 97, $409-438$.

Datta, A., Agarwal, S., 2004. Telecommunications and economic growth: a panel data approach. Applied Economics 36, $1649-1654$.

Demurger, S., 2001. Infrastructure development and economic growth: an explanation for regional disparities in china?. Journal of Comparative Economics 29, 95-117.

Dholakia, N., Sherry, J.F., 1987. Marketing development: a resynthesis of knowledge. Research in Marketing 9, 119-44.

Ding, L., Haynes, K.E., Liu, Y., 2008. Telecommunications infrastructure and regional income convergence in china: panel data approaches. The Annals of Regional Science 42, 843-861.

Drucker, P.F., 1986. The changed world economy. Foreign Affairs, 768-791.

Dubey, H., 2013. Efficient and accurate kNN based classification and regression. Master Thesis, International Institute of Information Technology Hyderabad, India.

Fan, P., Zhou, G., 2011. Analysis of the business model innovation of the technology of internet of things in postal logistics. Proceedings of Industrial Engineering and Engineering Management, IEEE Press, 532-536.

Fang, L., Wu, Z., 2006. Application of GM (1,3) in highway passenger capacity forecast of transportation system. Journal of Highway and Transportation Research and Development 26, 163-166.

Fleisher, B.M., Chen, J., 1997. The coast-noncoastal income gap, productivity, and regional economic policy in China. Journal of 
Comparative Economics 25, 220-236.

Goh, M., Charlene L., 2003. Logistics development in China. International Journal of Physical Distribution \& Logistics Management 33, 886-917.

Gunasekera, K., Anderson, W., Lakshmanan, T., 2008. Highway-induced development: evidence from Srilanka. World Development 36, 2371-2389.

Hernando, I., Núñez, S., 2004. The contribution of ICT to economic activity: a growth accounting exercise with Spanish firm-level data. Investigaciones Economicas 28, 315-348.

Hertz, S., Alfredsson, M., 2003. Strategic development of third party logistics providers. Industrial marketing management 32 , 139-149.

Holtz-Eakin, D., Newey, W., Rosen, H.S., 1988. Estimating vector autoregressions with panel data. Econometrica: Journal of the Econometric Society 56, 1371-1395.

Hong, J., 2007. Transport and the location of foreign logistics firms: the Chinese experience. Transportation Research Part A: Policy and Practice 41, 597-609.

Hong, J., Chu, Z., Wang, Q., 2011. Transport infrastructure and regional economic growth: evidence from China. Transportation 38, 737-752.

Hood, M.V., Kidd, Q., Morris, I.L., 2008. Two sides of the same coin? employing granger causality tests in a time series cross-section framework. Political Analysis 16, 324-344.

Hooi, L.H., Huang, W., Hong, J., 2014. Logistics and economic development: experience from china, Transport Policy 32, 96-104.

Kennedy, S., Parker, D.A., 2015. Building China's 'One Belt, One Road'. <http://csis. org/publication/building-chinas-one-belt-oneroad>.

Lai, H.H., 2002. China's western development program: its rationale, implementation, and prospects. Modern China 28, $432-466$.

Lakshmanan, T., 2011. The broader economic consequences of transport infrastructure investments. Journal of Transport Geography $19,1-12$.

Lau, H.C., Sim, M., Teo, K.M., 2003. Vehicle routing problem with time windows and a limited number of vehicles, European Journal of Operational Research 148, 559-569.

Layton, R.A., 1988. Industrial development and traditional distribution: are they compatible?. In: Kumcu, E. and Firat, A.F. (Eds.), Marketing and Development: Toward Broader Dimensions, Research Series in Marketing, Supp. 4, Greenwich, Conn. JAI Press, 1988, pp.173-198.

Levin, A., Lin, C., James C.C., 2002. Unit root tests in panel data: asymptotic and finite-sample properties. Journal of Econometrics, $108,1-24$

Lorentz, H.. Yew, W.C., Hilmola, O.P., 2007. Emerging distribution systems in Central and Eastern Europe: implications from two case studies. International Journal of Physical Distribution \& Logistics Management 37, 670-697.

Loustau, P., Morency, C., Trepanier, M., Gourvil, L., 2010. Travel time reliability on a highway network: estimations using floating car data. Transportation Letters 2, 27-37.

Madden, G., Savage, S.J., 2002. R\&D spillovers, information technology and telecommunications, and productivity in ASIA and the OECD. Information Economics and Policy 12, 367-392.

Man, J.Y., 1998. Transportation infrastructure and regional economic development in China. International Journal of Public Administration 21, 1307-1321.

McKinnon, A.C, Woodburn, A., 1996. Logistical restructuring and road freight traffic growth. Transportation 23, 141-161.

Mody, A., Wang, F., 1997. Explaining industrial growth in coastal China: economic reforms and what else?. The World Bank Economic Review 11, 293-325.

Muqiang, Z., 2009. Empirical study on the relationship between regional logistic capability and economic growth in Guangdong. Innovation 7, 5-8.

Nan, L., Li, Y., 2007. Interaction between logistics development and economic growth in China. Journal of Industrial Engineering \& Engineering Management 21, 151-153.

Naughton, B., 2007. The Chinese Economy: Transition and Growth. MIT Press, Cambridge.

Nievergelt, Y., 1983. The concept of elasticity in economics. SIAM Review 25, 261-265.

Osborne, J., Waters, E., 2002. Four assumptions of multiple regression that researchers should always test. Practical Assessment, Research \& Evaluation 8, 1-9.

Ozbay, K., Ozmen-Ertekin, D., Berechman, J., 2007. Contribution of transportation investments to county output. Transport Policy 14, 317-329.

Qian, X.Y., MA, C.X., 2007. Cointegration test for logistics and economic growth. Journal of Hunan University (Natural Sciences) 4 , 84-87.

Paflioti, P., Vitsounis, T.K., Tsamourgelis, I., Bell, M.G.H., 2014. Container seaports connectivity: a "concept" analysis. Proceedings of International Forum on Shipping, Ports and Airports (IFSPA) 2014: Sustainable Development in Shipping and Transport Logistics, Hong Kong, China.

Pages, L., Jayakrishnan, R., Cortes, C.E., 2006. Real-time mass passenger transport network optimization problems. Transportation Research Record: Journal of the Transportation Research Board 1964, 229-237.

Ravallion, M., Chen, S., 1997. What can new survey data tell us about recent changes in distribution and poverty?. World Bank Economic Review 11, 357-382.

Razzaque, M.A., 1997. Challenges to logistics development: the case of a third world country - Bangladesh. International Journal of Physical Distribution \& Logistics Management 27, 18-38.

Rodnikov, A.N., 1994. Logistics in command and mixed economies: the Russian experience. International Journal of Physical Distribution \& Logistics Management 24, 4-14.

Sahoo, P., Dash, R.K., Nataraj, G., 2010. Infrastructure development and economic growth in China. IDE-JETRO Discussion Paper 261.

Sedgwick, P., 2012. Pearson's Correlation Coefficient, BMJ 345. 
Shirley, C., Winston, C., 2004. Firm inventory behavior and the returns from highway infrastructure investments. Journal of Urban Economics 55, 398-415.

Speece, M.W., Kawahara, Y., 1995. Transportation in China in the 1990s. International Journal of Physical Distribution \& Logistics Management 25, 53-71.

Thurstone, L.L., 1931. Multiple factor analysis. Psychological Review 38, 406-427.

Tung, F.C., Chang, S.C., Chou, C.M., 2008. An extension of trust and TAM model with IDT in the adoption of the electronic logistics information system in HIS in the medical industry. International Journal of Medical Informatics 77, 324-335.

Uchimura, K., Hong, G., 1993. The Importance of Infrastructure on Economic Development. Latin America and Caribbean Regional Office, World Bank, Washington DC.

Wang, T.F. and Cullinane, K., 2006. The efficiency of European container terminals and implications for supply chain management. Maritime Economics \& Logistics 8, 82-99.

Zhang, Z., Figliozzi, M.A., 2010. A survey of China's logistics industry and the impacts of transport delays on importers and exporters. Transport Reviews 30, 179-194.

Zhao, W., He, H.S., Lin, Z.C., Yang, K.Q., 2006. Study of properties of Chinese railway passenger transport network. Acta Physica Sinica 55, 3906-3911. 